B Popovici, M Mitrica. Pediatric, Faculty of Medicine, 'Transilvania' University Brasov, Brasov, Romania

Introduction Congenital malformations are still a major cause of morbidity and mortality in newborns in Romania. The significant incidence and the difficulties of the management of this pathology are a reality which requires more attention and efforts.

Objective The aim of the study was to determine the incidence of congenital cardiac malformations (CCM) between 2000-2010, the risk factors and distribution of the CCM.

Material and method It was a retrospective study which included all the newborns with CCM who were admitted in our hospital. We had proceeded: clinical exam, laboratory tests, ECG, echocardiography.

Results From a total of 105968 children, 863 had congenital cardiac malformations $(0.81 \%)$. The main risk factors were: teratogenic factors (diabetes mellitus and alcoholism), cromosomal defects, multifactorial transmision. The most frequent malformations were noncyanotic as atrial septal defects and ventricular septal defects $(88.06 \%)$ vs cyanotic defects $(11.93 \%)$. In most of the cases the diagnosis was estabilished after birth and only $1.73 \%$ ( $\mathrm{nr}=15$ cases) had prenatal diagnosis. The outcome of children was: 504 newborns $(58.40 \%)$ had needed medical treatment but no surgical corrective procedures, $223(25.84 \%)$ had had paleative or corrective surgical treatment and 136 (15.75\%) had died because of complications or of the imposibility of a proper surgical treatment.

Conclusions The diagnosis of cardiac malformation is not a problem anymore due to echocardiography but, unfortunatly, prenatal diagnosis is still difficult. The most cases are noncyanothic malformations. The outcome is related with the type of CCM, complications and possibility of a proper treatment.

\section{INTERNATIONAL SURVEY ON THE USE OF PROPHYLACTIC INDOMETHACIN IN EXTREMELY PRE-TERM INFANTS}

doi:10.1136/archdischild-2012-302724.1151

${ }^{1} Y$ Singh, ${ }^{1} \mathrm{~V} \mathrm{Ng},{ }^{2} \mathrm{~S}$ Boynton. ${ }^{1}$ Neonatal Medicine; ${ }^{2}$ Paediatric Cardiology, The Leeds Teaching Hospitals NHS Trust, Leeds, UK

Background Prophylactic trials with indomethacin have consistently revealed short term benefits like a decreased need for PDA ligation (RR 0.51), decreased incidence of pulmonary haemorrhage (RR 0.35), and serious IVH (RR 0.66).

The use of indomethacin prophylaxis increased after Ment trial while decreased after TIPP trial as no long term improvement in neurodevelopmental outcome was reported. However, TIPP trial was under-powered to study long term neurodevelopmental outcome.

Aims and objectives To find out the current practice on use of prophylactic indomethacin in extremely pre-term infants.

Design and methods Questionnaire based international survey from 51 tertiary neonatal units across 9 countries (including United Kingdom, USA, New Zealand and Australia). The neonatologists were contacted via email or telephone to find out current practice on use of prophylactic indomethacin in extremely pre-term infants. Results 5 of $51(10 \%)$ tertiary neonatal units use prophylactic indomethacin in extremely pre-term infants. In the UK 3 of the 44 units $(6.8 \%)$ use prophylactic indomethacin. 2 units in the USA use prophylactic indomethacin.

Practice varies across the units -2 units use prophylactic indomethacin for all infants $<28$ weeks of gestation while other units use on targeted infants.

Conclusion Use of prophylactic indomethacin declined after TIPP trial but it's use has further declined because of unavailability (short of supply from manufacturer). In the UK use of prophylactic indomethacin has declined from 5 to 3 centres recently. Our survey also showed that some neonatal units would like to use prophylactic indomethacin but indomethacin is not available currently.

\section{PROSTAGLANDIN E $\mathrm{E}_{1}$ USE IN THE TRANSFER OF INFANTS WITH SUSPECTED DUCT DEPENDENT CONGENITAL HEART DISEASE}

doi:10.1136/archdischild-2012-302724.1152

${ }^{1,2} \mathrm{~N}$ Gupta, ${ }^{2,3} \mathrm{COF}$ Kamlin, ${ }^{2.4} \mathrm{M}$ Stewart, ${ }^{5} \mathrm{M}$ Cheung, ${ }^{4} \mathrm{~N}$ Patel. ${ }^{1}$ Neonatal Unit, John Radcliffe Hospital, Oxford, UK; 'Newborn Emergency Transport Services (NETS), Royal Children Hospital; ${ }^{3}$ Department of Newborn Research, Royal Womens Hospital; ${ }^{4}$ Neonatal Unit, Royal Childrens Hospital; ${ }^{5}$ Department of Cardiology, Royal Children Hospital, Melbourne, VIC, Australia

Background Transport of infants with suspected duct dependent congenital heart disease (DDCHD) represents a diagnostic and therapeutic dilemma, specifically in relation to use of prostaglandin $\mathrm{E}^{1}$ $\left(\mathrm{PGE}_{1}\right)$ to maintain ductal patency.

Aims To evaluate factors influencing, and consequences of, $\mathrm{PGE}_{1}$ use in transport of infants with suspected DDCHD or persistent pulmonary hypertension (PPHN).

Methods Retrospective study of infants' $\leq 10$ days old with suspected DDCHD/PPHN transferred to the Royal Children's Hospital, Melbourne, by NETS (Victoria) identified from transport and hospital databases.

Results Of 142 eligible infants, 81 had DDCHD, 51 had PPHN and 10 had neither. Diagnostic accuracy of DDCHD by transport team was $77 \%$. PGE was commenced in $50 \%$ of infants, $63 \%$ of DDCHD group, and $19 \%$ of non-DDCHD group.

"Time critical" transfers were significantly associated with PGE use; transfer distance and air/land were not. PGE $\mathrm{P}_{1}$ use was significantly associated with the presence of cyanosis, abnormal pulses and lower initial $\mathrm{SpO}_{2}$ and $\mathrm{PaO}_{2}$.

Ventilation and inotrope use during transfer were significantly higher in infants with DDCHD who received $\mathrm{PGE}_{1}$, than those who did not (both $\mathrm{P}$ 0.007). Use of $\mathrm{PGE}_{1}$ significantly shortened length of stay in PPHN but not DDCHD patients. There was no significant difference in death rates between $\mathrm{PGE}_{1}$ and no-PGE group.

Conclusions Although the ability of transport personnel to differentiate DDCHD from PPHN and correctly administer PGE was high, $35 \%$ of infants with DDCHD were transferred without $\mathrm{PGE}_{1}$. Cyanosis, abnormal pulses and initial hypoxemia influenced the decision to start $\mathrm{PGE}_{1}$. $\mathrm{PGE}_{1}$ may improve outcome in PPHN.

\section{BRAIN NATRIURETIC PEPTIDE (BNP) MEASUREMENT IN THE PREDICTION OF PATENT DUCTUS ARTERIOSUS (PDA) SEVERITY AND NEED FOR LIGATION}

doi:10.1136/archdischild-2012-302724.1153

${ }^{1}$ SA Ahmed, ${ }^{2} \mathrm{R}$ Joseph, ${ }^{2} \mathrm{C}$ Tzivinikos, $1 \mathrm{I}$ Ossuetta, ${ }^{3} \mathrm{D}$ Housley. ${ }^{\text {NNeonatology; }}{ }^{2}$ Luton 8 Dunstable Hospital NHS Foundation Trust; ${ }^{3}$ Biochemistry, Luton \& Dunstable Hospital NHS Foundation Trust, Luton, UK

Aim Has Brain Natriuretic Peptide (BNP) role in the prediction of Patent Ductus Arteriosus (PDA) severity and need for ligation. Method

- Prospective study

- July 2010 to Feb.2011

- Single tertiary neonatal unit

- BNP level was done in babies $<30$ wks with the diagnosis of PDA.

- Data was collected from SEND database and medical notes.

\section{Results}

- 35 babies of which one baby was excluded as sample was unsuitable.

- Male: Females 1.25:1

- Birth weight ranges from $410 \mathrm{gm}$ to $1200 \mathrm{gm}$.

- Based on the BNP value babies are divided into 4 groups. 
Group 1: BNP value 0 to 500, of 25 babies 11 had at least 1 course of Ibuprofen of which 2 babies PDA closed, 9 needed ligation. Of the 25 babies 14 had contraindications for medical treatment of which 6 babies needed PDA ligation.

Group 2: BNP value of 501 to 1000, of the 4 babies all were treated with Ibuprofen only 2 babies PDA closed and 2 babies PDA needed ligation.

Group 3: BNP value of 1001 to 2000, of the 2 babies all treated with Ibuprofen 1 baby's PDA closed and 1 baby's PDA needed ligation.

Group 4: $\mathrm{BNP}>2000$, of 3 babies 2 were treated with Ibuprofen, PDA not closed needing ligation and 1 baby not treated with PDA closed.

Conclusion In our study group 59\% (20/34) of babies with PDA needed ligation. BNP level did not predict severity or early referral for PDA ligation in our study group. We need further study with large sample and randomization to support our study conclusion.

\section{SPONTANEOUS CLOSURE OF PATENT DUCTUS ARTERIOSUS IS PRESUMABLE IN VERY LOW BIRTH WEIGHT INFANTS}

doi:10.1136/archdischild-2012-302724.1154

1,2J Sirc, 'J Kucera, 1,2J Semberova, ${ }^{1,2 Z}$ Stranak. 'Neonatal Department, Ustav Pro Peci o Matku a Dite; ${ }^{2}$ Third Faculty of Medicine, Charles University, Prague, Czech Republic

Background and Aims Emerging evidence suggests, that routine pharmacological or surgical closure of patent ductus arteriosus (PDA) is not beneficial for preterm infants. Informations about natural closure of ductus are lacking. Aim of the study was to evaluate untreated preterm infants with PDA.

Methods Retrospective observational study. Very low birth weight infants born during the 18 months period were enrolled. Only babies with severe signs of hemodynamically significant PDA were treated. All patients were followed until closure of PDA (clinically or echocardiographically approved).

Results 198 infants with mean birth weight $1113 \pm 690$ grams and mean gestation age $28.4 \pm 7$ weeks were eligible for the study. 22 $(12 \%)$ died before discharge for morbidities directly unrelated to PDA. 13 patients were treated -6 with ibuprofen and 8 were ligated. One neonate had residual flow through the PDA after ligation. 15 (7.5\%) have been discharged with PDA. From them, 8 had spontaneous closure in the first year of corrected age and 1 in the second year. 6 infants have a small, hemodynamically nonsignificant PDA and are in cardiology follow up.

Conclusions Routine treatment of PDA should be abandoned. Chance of spontaneous closure is likely during the first year of corrected age. Cardiological and long term neurological follow up is needed for infants with PDA.

\section{SURGICAL LIGATION OF PATENT DUCTUS ARTERIOSUS IN PRETERMS LESS THAN 30 WEEKS GESTATION IN A TERTIARY NEONATAL UNIT}

doi:10.1136/archdischild-2012-302724.1155

R Kumar, L Podugu, SV Rasiah. Department of Neonatology, Birmingham Women's NHS Foundation Trust, Birmingham, UK

Background Patent ductus arteriosus is inversely related to gestational age. It remains a significant morbidity and challenge to manage in extremely preterm babies. Medical therapy reduces the need for surgical ligation.

Aim To audit our management of PDA and the need for surgical ligation.

Methods The Badger database was interrogated for babies less than $30+0$ weeks gestation who had a PDA. Their management and outcomes were audited over a 3 year period from 01/04/09 to 31/03/12

Results In the last 3 years, there were 300 babies less than $30+0$ weeks gestation who were admitted to our tertiary neonatal unit. PDA was confirmed on echocardiography in 190 (63\%) babies. 72 (38\%) babies were treated with Indomethacin (62 complete and 10 incomplete course: 5 renal impairment, 3 thrombocytopenia and 2 NEC). 25 (13\%) babies had a surgical ligation of their PDA (The median gestational age at birth was 24 weeks and median birth weight was 725 grams). 13 (52\%) babies who underwent ligation, received at least one complete course of Indomethacin. Median age at ligation was 30 days of life. There was no surgical morbidity or mortality from the PDA ligation. 67 babies died and 233 babies were discharged home. 25 babies needed home oxygen of which 21 previously had a significant PDA.

Conclusion Despite medical therapy, there is a small population of extremely preterm babies who have a recalcitrant PDA that need surgical ligation. Early identification with serial echocardiography and proactive management of these babies might improve their respiratory morbidities.

\section{HYPOXIC PERINATAL CARDIOMYOPATHY-DIAGNOSIS AND EVOLUTION}

doi:10.1136/archdischild-2012-302724.1156

'L Dimitiru, ${ }^{2} \mathrm{Ag}$ Dimitiru, ${ }^{3} \mathrm{M}$ Stamatin. ${ }^{1}$ Pediatric Cardiology, Medex Medical Center; ${ }^{2}$ Pediatric Cardiology: ${ }^{3}$ Neonatology, University of Medicine and Pharmacy, lasi, Romania

Purpose To present the main aspects of myocardial injury secondary to perinatal hypoxia.

Methods/patients 88 newborns aged 0-14 days, normal birth weight, with perinatal hypoxia (Apgar score 3-7), receveing resuscitation, without major congenital heart diseases. All cases: clinical exam, ECG, chest X-ray (Rx.CT), Doppler echocardiography (ECHO). Most of patients were evaluated and after 6 months.

Results The patients had mainly signs of neurological post hypoxic suffering, 8 cases signs of severe heart injury (cardiomegaly, respiratory distress, cyanosis, peripheric hypoperfusion), other cases: systolic murmur (64) and signs of PPHN (8). Chest X-ray: cardiomegaly (32). ECG: severe left ventricle (LV) repolarization disturbances and low voltage of ORS complexes (37), without ischemic changes. ECHO at 2-7 days of life: * the absence of severe congenital cardiac anomaly; *permeability of foramen ovalae (100\%); mild to severe tricuspid insufficiency, RV and RA dilation (29); sometimes rightleft shunt through the FO *myocardial hypertrophy (42) mainly IVS(29), signs of PPHN(6); increased myocardial performance index (44 cases), the systolic dysfunction (5) and severe LV diastolic dysfunction (45 cases). New evaluation at 6 months showed; reduction of the myocardial hypertrophy and of tricuspid regurgitation, normal LV systolic and diastolic function.

Conclusions The perinatal hypoxia can induce a important myocardial injury as hypoxic ischemic myocardopathy or transient post hypoxic hypertrophic cardiomyopathy $(62.2 \%$ of patients), the signs of cardiovascular suffering missing often. Echo is the main method for diagnosis and follow up of perinatal hypoxic cardiomyopathy and is necessary performed from the first week of life.

\section{A REPORT OF TWO CASES OF GLUCOCORTICOID ASSOCIATED CARDIAC DYSFUNCTION IN NOONAN SYNDROME}

doi:10.1136/archdischild-2012-302724.1157

${ }^{1} \mathrm{M}$ Boyle, ${ }^{2} \mathrm{M}$ Cotter, ${ }^{1} \mathrm{O}$ Franklin, ${ }^{1} \mathrm{~A}$ Foran. ${ }^{1}$ Neonatology; ${ }^{2}$ Haematology, Rotunda Hospital, Dublin, Ireland

Background and Aims To review the potential exacerbating factors of cardiac function in 2 cases of Noonan syndrome. 